\title{
Combining Unthrottled Operation with Internal EGR under Port and Central Direct Fuel Injection Conditions in a Single Cylinder SI Engine
}

\author{
Alasdair Cairns, Alan Todd
}

MAHLE Powertrain Ltd

Hermann Hoffman

MAHLE International GmbH

Pavlos Aleiferis, John Malcolm

University College London

Copyright @ 2009 SAE International

\begin{abstract}
This experimental work was concerned with the combination of internal EGR with an early inlet valve closure strategy for improved part-load fuel economy. The experiments were performed in a new spark-ignited thermodynamic single cylinder research engine, equipped with a mechanical fully variable valvetrain on both the inlet and exhaust. During unthrottled operation at constant engine speed and load, increasing the mass of trapped residual allowed increased valve duration and lift to be used. In turn, this enabled further small improvements in gas exchange efficiency, thermal efficiency and hence indicated fuel consumption. Such effects were quantified under both port and homogeneous central direct fuel injection conditions. Shrouding of the inlet ports as a potential method to increase in-cylinder gas velocities has also been considered.
\end{abstract}

\section{INTRODUCTION}

Evolving emissions legislation and concerns for diminishing fuel reserves continue to prompt the automotive industry to seek alternative modes of engine operation. In recent years, European $\mathrm{CO}_{2}$ emissions targets have been met through increased diesel sales. However, the distillation of crude oil results in high proportions of both gasoline and diesel fuel (1) and ultimately this has resulted in Europe becoming "diesel lean". In order to meet global emissions goals in the short-to-medium term, it will be necessary to improve the fuel consumption of the gasoline engine.

The ability to vary the inlet and exhaust valve events of the gasoline engine is well-known to facilitate improved compromise between performance, fuel economy and emissions. Variable Valve Timing (VVT) is an established technique for improving the fuel economy of the gasoline engine (2-4). There are several mechanisms by which VVT influences fuel consumption:

- Increasing or delaying valve overlap, which increases trapped residuals and reduces pumping work

- Late Inlet Valve Closure (IVC), which decreases pumping losses

- Late Exhaust Valve Opening (EVO), which can increase expansion work

As a result, fuel economy can typically be improved by up to $~ 5 \%$ over the European drive cycle. The choice of optimum VVT strategy is highly dependent on exhaust manifold design, compression ratio, cam phasing limits due to clash, part-load residual dilution tolerance and the importance of Wide Open Throttle (WOT) performance relative to part-load fuel consumption and emissions. A

\footnotetext{
The Engineering Meetings Board has approved this paper for publication. It has successfully completed SAE's peer review process under the supervision of the session organizer. This process requires a minimum of three (3) reviews by industry experts.

All rights reserved. No part of this publication may be reproduced, stored in a retrieval system, or transmitted, in any form or by any means, electronic, mechanical, photocopying, recording, or otherwise, without the prior written permission of SAE. ISSN 0148-7191

Positions and opinions advanced in this paper are those of the author(s) and not necessarily those of SAE. The author is solely responsible for the content of the paper.

SAE Customer Service: Tel: $\quad 877-606-7323$ (inside USA and Canada)

Tel: $\quad$ 724-776-4970 (outside USA)

Fax: 724-776-0790

Email: CustomerService@sae.org
}

SAE Web Address: http://www.sae.org 
dual-independent VVT strategy offers high overlap potential and reasonable compromise between maximising WOT torque and minimising part-load fuel consumption and emissions. This is particularly true for hardware combinations that benefit from high overlap at both WOT (for scavenging) and part-load (to increase trapped residuals). An alternative strategy that could be used is high overlap retard, which can potentially give even lower fuel consumption than a maximum overlap strategy (5). However, WOT torque can be compromised, particularly at low speed unless very wide range, fast response cam phaser units can be used (6).

In relatively recent years, there has also been considerable interest in fully variable valvetrain systems for additional improvements, such as:

- Further reduction in throttling losses via load control directly at the inlet valve(s)

- Increased thermal efficiency through greater expansion ratio

- Reduced tailpipe emissions under cold-start (direct fuel injection) conditions via late Inlet Valve Opening (IVO)

Numerous fully variable valvetrain strategies exist depending on application, but the currently reported work is most concerned with those SI engine strategies claiming to enable improved part-load fuel efficiency. During his useful study in a similar vein, Tuttle compared the effects of Late Inlet Valve Closing (LIVC) and Early Inlet Valve Closing (EIVC) in a single cylinder research engine. In early experiments (7), IVC was delayed through $60-96^{\circ}$ crank. Fuel consumption was observed to reduce by up to $6.5 \%$ and was accompanied by lower engine-out emissions of NOx ( 24\%) but similar hydrocarbon levels. Regardless, Tuttle concluded that $96^{\circ}$ was the maximum delay that could be tolerated due to loss of effective compression ratio, which would significantly limit the attainable speed-load map (assuming no external compression was available). In subsequent work (8), it was concluded that the EIVC strategy was favourable for part-load, allowing dethrottled operation over a wider speed-load window, albeit reliant on $200^{\circ}$ crank range of inlet valve closing.

To date, there still remains significant research interest in the thermodynamic effects of EIVC operation. For example, in a recent alternative study Cleary and Silvas (9) investigated EIVC at part-load (1300 rpm/3.3bar net IMEP) in a single cylinder PFI engine. It was observed that such a strategy led to reduced in-cylinder turbulence at the conditions studied, associated with the increased time under closed valve conditions. In turn, this resulted in prolonged combustion duration, reduced in-cylinder gas temperatures, reduced engine-out emissions of $\mathrm{NOx}$ (up to 25\%) and increased values of unburned hydrocarbons (also 25\%). The deterioration in burn rate could be reduced by switching to a LIVO strategy but, under the reduced valve duration conditions tested, the pumping losses were worse than the conventional throttled benchmark case.
The benefits achieved by EIVC operation are highly dependent on the valvetrain system employed. At one end of the spectrum, various electro-magnetic and electro-hydraulic systems have been proposed. Such camless systems have been reported to allow the greatest potential for reduction in SI engine breathing losses $(10,11)$ and/or can be used to realize advanced modes of operation such as Controlled Auto Ignition (12, 13). However, in general these systems often still have significant issues to overcome including packaging, noise and cost.

The majority of fully variable valvetrain systems entering production have been mechanically based as these arguably present a viable step on a cost-benefit basis. For example, Unger et al. (14) recently summarised the design and development of the second generation Valvetronic system, capable of providing up to $\sim 12 \%$ reduction in fuel consumption at part-load. Improvements claimed in the second-generation iteration included more aggressive valve lift profiles, reoptimization of the inlet port masking, friction reductions and integration of the control system within the main engine control unit. Elsewhere, Shimizu and co-workers (15) recently reported on the benefits of the new production Valvematic system, a well-packaged continuously variable valve lift system offered in conjunction with dual VVT. These workers reported up to $\sim 10 \%$ improvement in fuel economy could be achieved during typical part-load operation, with similar percent improvement in power. Another mechanical fully variable system recently introduced is the Nissan VVEL $(16,17)$, which enables relatively aggressive inlet lift profiles to be used with fuel economy benefits similar to those above. Elsewhere, Sellnau and co-workers (18) have demonstrated how two-stage mechanical valve actuation can allow viable further compromise on a cost-benefit basis, achieving $5.5 \%$ improvement in fuel economy and $\sim 46 \%$ reduction in NOx over an EPA drive cycle.

The above systems were all used in conjunction with port fuel injection. However, the combination of EIVC with homogeneous Direct Injection (DI) has also begun to warrant interest, with the potential for further fuel savings if used together with increased compression ratio. For example, workers on the "Hotfire" collaborative project recently examined such effects in both optical and thermodynamic single cylinder SI engine assemblies $(19,20)$. During this study, greatest fuel consumption benefits could be achieved if just one of the two inlet valves was actuated. However, the swirl dissipated quickly once the valve closed and the fuel economy benefits recorded varied substantially depending on which of the two inlet valves was activated.

The main objective of the currently reported work was to improve present understanding of the benefits of internal EGR when applied to an engine already operating under unthrottled conditions. Both port and homogeneous central direct fuel injection charge preparation has been considered. 


\section{EXPERIMENTAL SETUP}

\section{ENGINE ASSEMBLY}

The experiments were performed in a new, naturally aspirated single cylinder four-valve per cylinder spark ignition research engine. Some general details of the unit are presented below in Table 1.

\begin{tabular}{|l|l|}
\hline No of cylinders & 1 \\
\hline Bore $(\mathrm{mm})$ & 82.5 \\
\hline Stroke $(\mathrm{mm})$ & 88.9 \\
\hline Geometric compression ratio & $9.8: 1$ \\
\hline Variable Valve Timing & $\begin{array}{l}\text { Fully Variable (Inlet \& } \\
\text { Exhaust) }\end{array}$ \\
\hline Fuel injection & $\begin{array}{l}\text { Interchangeable (port, side } \\
\text { direct or central direct) }\end{array}$ \\
\hline Spark plug & NGK single electrode \\
\hline Ignition coil & Bosch coil-on-plug \\
\hline Fuel & 95 RON unleaded gasoline \\
\hline
\end{tabular}

Table 1: Basic engine characteristics

The base engine assembly is illustrated in Figure 1. The engine was designed to provide a low-cost single cylinder assembly. As such, the bottom-end was based on a modified industrial Lister-Petter diesel engine subassembly, re-fitted with a prototype water-cooled barrel and bespoke con-rod and piston assemblies. Sections through the prototype cylinder head assembly are illustrated in Figure 2. This head was designed to allow study of port, side direct or central direct fuel injection using a common platform. The ports and combustion chamber geometry were based on those of an Audi FSI production engine. However, three variants of piston were available for the different modes of fuel injection, as illustrated in Figure 3. For port fuel injection, a production fuel injector and prototype flat-topped piston were available. For side direct injection, the Audi production parts could be used. Finally, any of the pistons could be used for central DI operation, depending on whether homogeneous or stratified operation was required. In DI mode, the head was designed to accommodate either a solenoid multi-hole or production piezo injector.

This new modular single cylinder assembly also allows straightforward conversion between the existing thermodynamic setup and fully optical operation, with the latter demonstrated recently under both port and side direct fuel injection operation $(21,22)$. The currently reported work was only concerned with thermodynamic operation. The port fuel injection setup was initially examined, with the fuel spray targeting the back of the inlet valves as per a typical production engine application. Secondly, initial results from central DI operation have been obtained, which involved use of the solenoid multi-hole fuel injector. These initial tests were concerned with the effects of fuel injection on combustion, performance and emissions without variation in compression ratio (itself intended to be studied later on). In DI mode, the flat-topped piston was still employed, which was considered to be acceptable for the homogeneous operation intended.

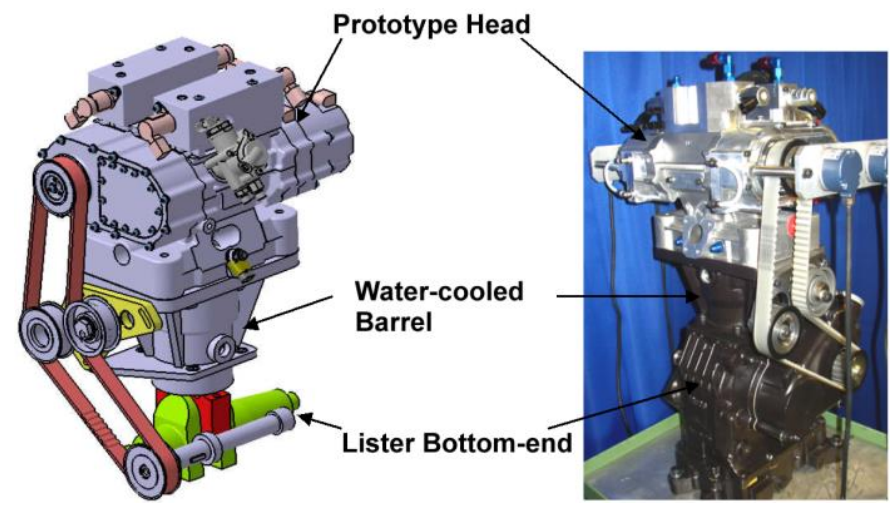

Figure 1: Base engine assembly (thermodynamic setup)

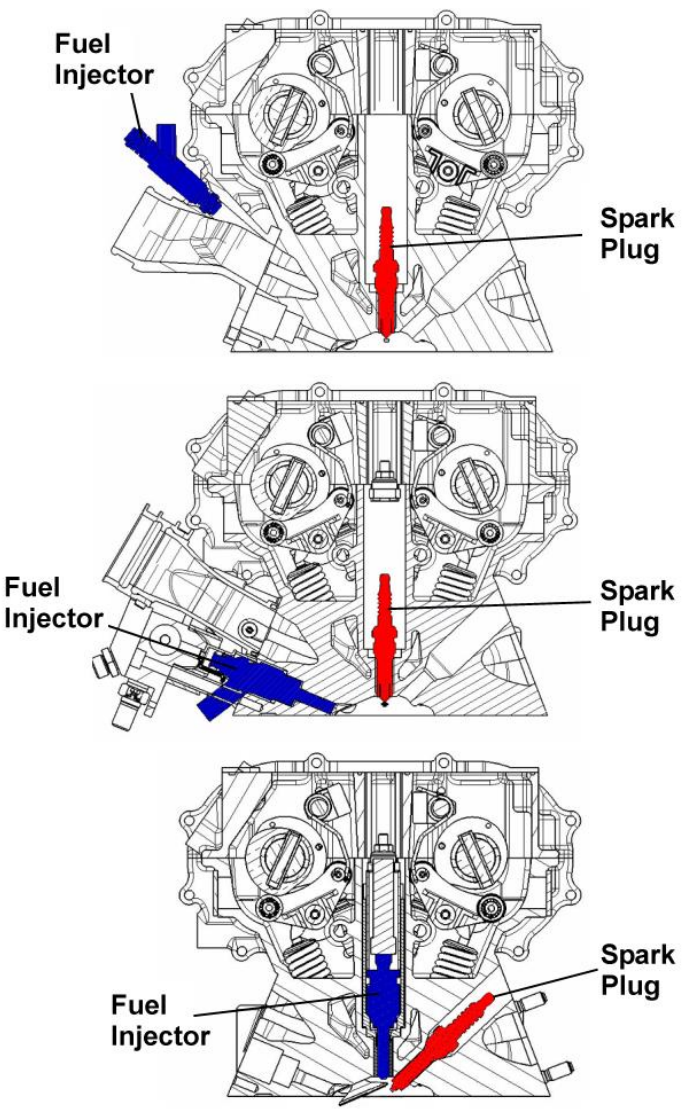

Figure 2: Cylinder head assembly showing port, side direct or central direct fuel injection using a common hardware platform

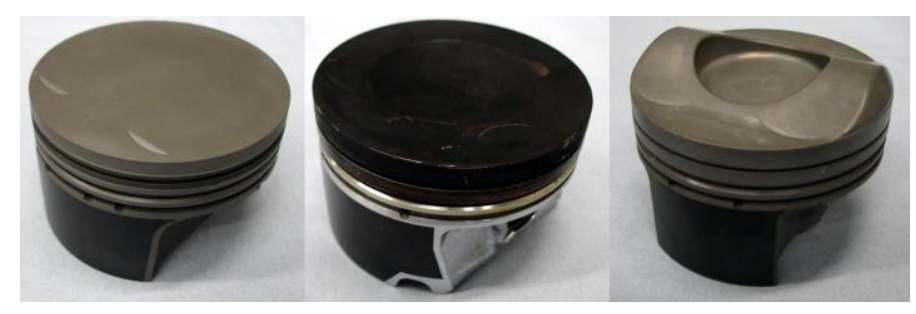

Figure 3: Flat-topped, shallow central bowl and deep central bowl piston assemblies 
The prototype cylinder head included a mechanical fully variable valvetrain assembly, fitted to both the inlet and exhaust. The system used was an evolution of the MAHLE Variable Lift and Duration (VLD) mechanism, previously introduced in detail elsewhere $(23,24)$. In brief, the system is based on a shaft-in-shaft cam operating principle. An example of an inlet VLD mechanism is illustrated in Figure 4. The two opening cams are pressed on to the outer shaft. These cams are equivalent in profile and must open the two inlet valves in a synchronous fashion via the lever assembly. The opening cam contours were designed so that, if no closing cam were available, the inlet valves would remain open at maximum lift for a prolonged period before eventually closing in a safe manner. However, such operation is hypothetical as the closing cam is available and pinned to the inner shaft. The phase of this closing cam, relative to the opening cam, can be advanced so as to close the valve earlier and reduce the valve lift and duration in proportion. The profiles of the cams were designed so as to ensure acceptable dynamic forces were produced regardless of phase.

In summary, the opening and closing cams act in tandem to produce a mean cam (and hence valve) lift curve. By advancing the phasing of the inner shaft relative to the outer shaft, the closing of the valve is advanced, hence allowing reduced lift and duration to be achieved. The phasing of the closing cam was controlled using a prototype wide range ( $140^{\circ}$ crank) hydraulic cam phaser, denoted in Figure 5 as the "VLD Phaser". In order to then achieve fully variable valvetrain operation, a second hydraulic VVT cam phaser was fixed to the outer tube, providing $40^{\circ}$ crank timing range. Similar ranges were available on the exhaust.

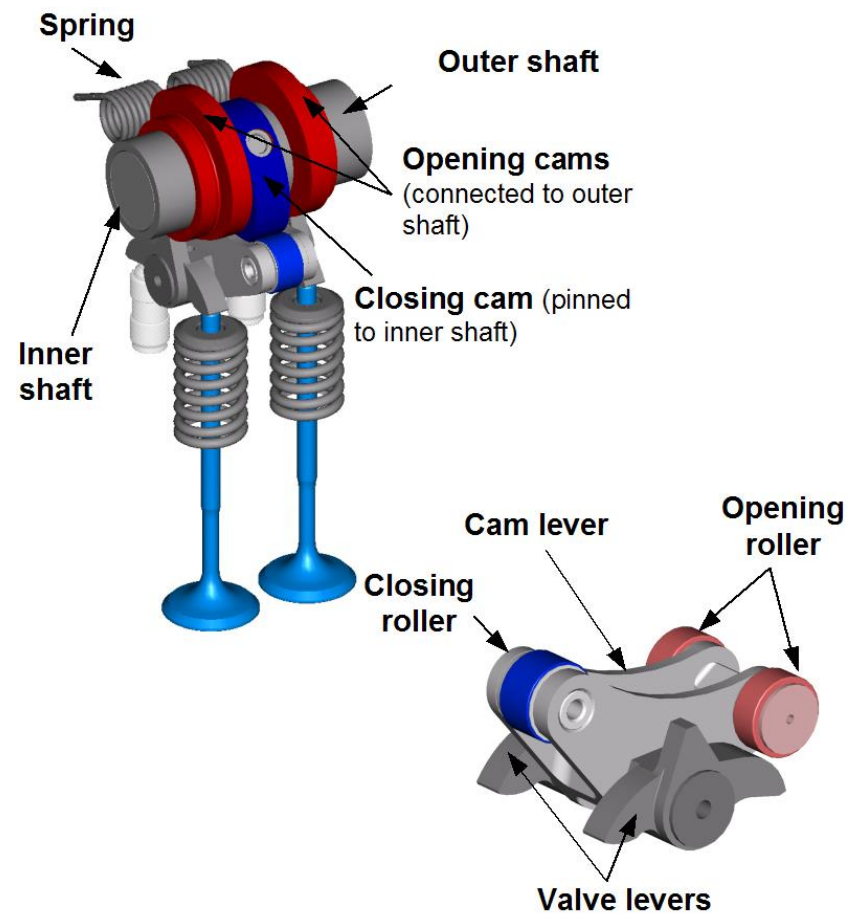

Figure 4: Key VLD components (example shown for inlet VLD operation)

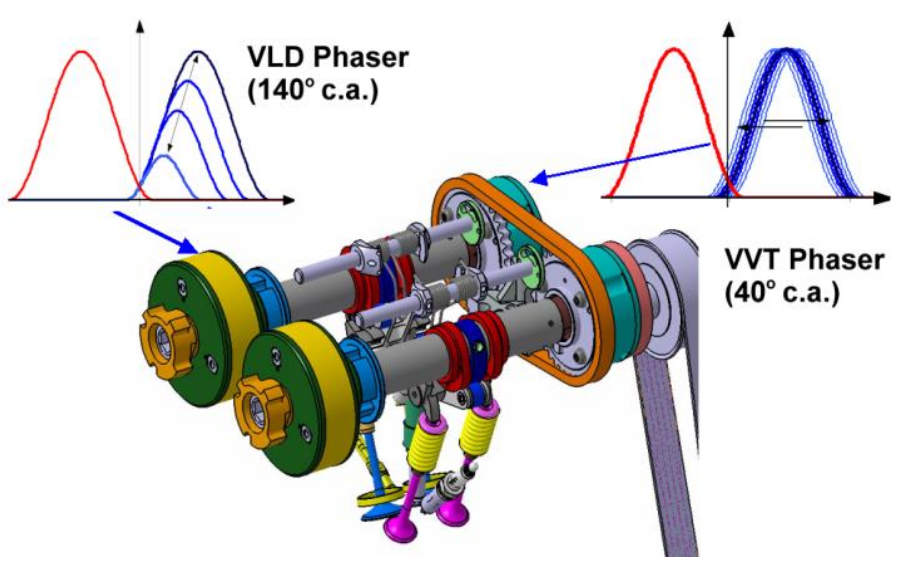

Figure 5: Single cylinder VLD assembly with the VLD and VVT cam phasers of the inlet camshaft identified

\section{VALVE LIFT MEASUREMENTS}

One main objective of the current work was to study the combined effects of unthrottled operation and internal EGR on combustion, performance and emissions. An illustration of the valve strategies so far examined is shown in Figure 6 . The experiments involved study of EIVC at varied degrees of valve overlap. The exhaust VLD cam phaser remained inactive and was set for maximum valve lift throughout the experiments.

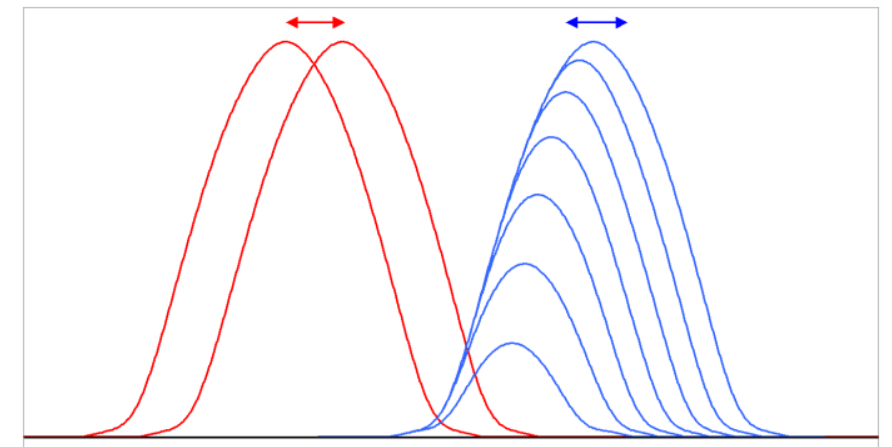

Figure 6: Illustration of the valve timing strategies studied in the current work (continuously variable inlet valve lift, dual independent VVT)

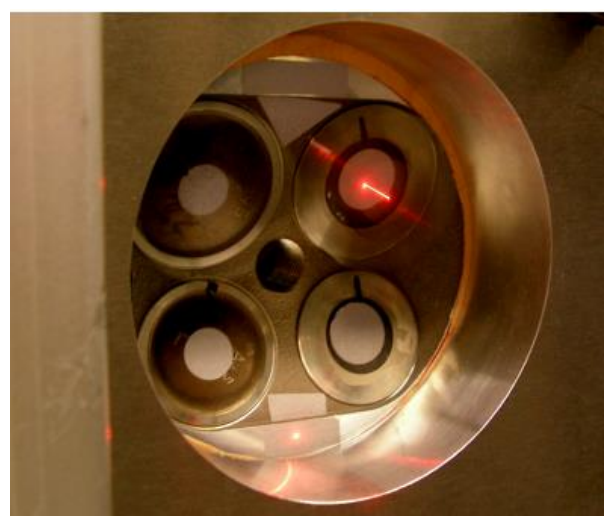

Figure 7: Example cylinder head fitted to the valve motion rig with the laser beam directed at one inlet valve 
The valve lift profiles were designed to maintain acceptable dynamic loads at engine speeds up to $6500 \mathrm{rpm}$. Prior to running the test engine, the valve lift versus duration was measured. One set of valves were spot-faced and fitted to the cylinder head sub-assembly. This sub-assembly was itself then fitted to an in-house valve motion measurement rig. In brief, this involved coupling the cylinder head cam drive to an in-line asynchronous electric motor. The head was clamped inline with the motor using a special mounting plate. A laser differential vibrometer system was then used to obtain direct valve velocity measurements via the laser Doppler interferometry technique, as illustrated in Figure 7 . The valve lift was estimated via the so-called fringe counting method, with a measurement resolution of $5 \mu \mathrm{m}$. During the tests, the cylinder head oil circuit was connected to an oil conditioning rig that controlled oil temperature and pressure to engine-like motoring conditions $\left(90^{\circ} \mathrm{C} \pm 2^{\circ} \mathrm{C}\right.$, 3bar gauge). The measurements obtained from one inlet valve at 750rpm (1500rpm crank) are illustrated in Figure 8. The valve duration is expressed from end-of-ramp to end-of-ramp, determined directly from valve acceleration profiles. In conclusion, such measurements cannot directly account for variation in lift versus crank angle due to firing engine conditions (e.g. torsional vibrations) but were still considered to be acceptable for approximating the valve lift from the known positions of the camshafts and phasers.

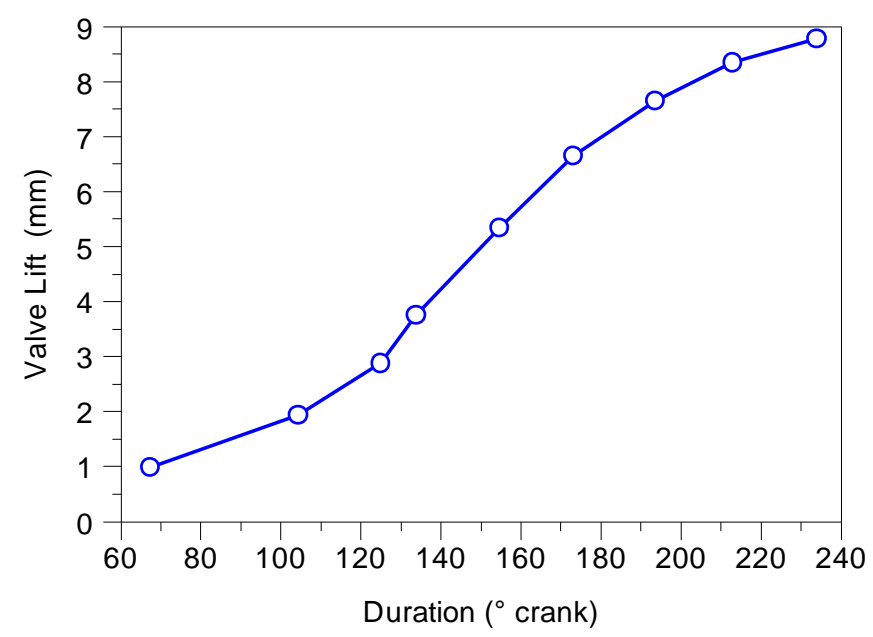

Figure 8: Inlet valve lift versus duration measurements obtained on a motoring valve motion rig (1500rpm crank)

\section{TEST APPARATUS}

During the tests, the cylinder head was fitted with a Kistler 6041A water-cooled in-cylinder pressure transducer, the face of which was mounted flush with the combustion chamber walls. Pressure data acquisition was performed using a SMETEC Combi system. The corresponding pressure data analysis was performed using AVL Concerto Version 3.8. Corresponding thermodynamic parameters were evaluated as the average of values compiled over 300 engine cycles. The engine-out emissions were sampled using a Horiba MEXA 9100 analyser. Fuel flow measurements were performed using a coriolis fuel flow meter assembly, calibrated in-situ to provide a maximum reading error of $<0.5 \%$ at the minimum fuel flows reported.

\section{RESULTS}

\section{PORT FUEL INJECTION}

\section{EIVC \& Inlet VVT Effects}

Initially, the engine was operated in PFI mode. The objective of these first tests was to study EIVC when combined with internal EGR, such as if the engine were to be fitted with a fully variable valvetrain on the inlet and fixed valvetrain on the exhaust. Shown in Figure 9 are corresponding maps produced at $1500 \mathrm{rpm} / 3.2 \mathrm{bar}$ IMEPn (MBT spark timing, $\lambda=1$, 95RON pump gasoline). This net IMEP was equivalent to that generated in a suitable multi-cylinder production engine at a reference brake load of 2.62bar BMEP (a mapping site used by some OEMs). The "baseline" data point marked on the map indicates the valve timing settings for a typical nonVVT engine, with overlap set to allow acceptable performance across the speed-load map. This valve timing setting falls within the typical window for a nonVVT engine as illustrated in Appendix A. During the experiment, the exhaust valve lift remained locked at the maximum value of $8.9 \mathrm{~mm}$. EVC was also held fixed at $9^{\circ}$ aTDC. The fuel injection timing also remained constant and was set for best fuel economy at the "baseline" condition (EOI $=400^{\circ} \mathrm{bTDCF}$ ). The most advanced IVO setting shown was governed by valve-topiston clash, with $1 \mathrm{~mm}$ clearance maintained.

Shown in the corners of the valve lift map are four valve lift cartoons that help illustrate the valve events occurring in different areas of the map. In the top right-hand corner, the engine inlet was throttled, with maximum valve lift and minimum valve overlap applied. In the bottom right-hand corner, IVO was advanced for increased overlap and internal EGR. Moving horizontally from right to left, in the bottom left-hand corner the engine was operating with the highest possible valve overlap and also an unthrottled EIVC strategy. Finally, in the top left-hand corner, the unit was operating with minimum valve overlap and EIVC.

In summary, up to $11 \%$ improvement in net Indicated Specific Fuel Consumption (ISFCn) was possible at this site when combining EIVC and inlet VVT. Of this benefit, $\sim 3 \%$ was attributable to VVT as seen in the bottom-right hand corner of the ISFC map. The remaining $8 \%$ was associated with EIVC. The inlet valve duration and lift at the best ISFC site were $112^{\circ} \mathrm{crank} / 2.23 \mathrm{~mm}$. The corresponding standard deviation in gross IMEP $(\sigma$ IMEP) remained well within acceptable limits $(0.06 \mathrm{bar})$. It was therefore concluded that higher amounts of internal EGR could be tolerated in this engine at this site. Other combustion and emissions effects are discussed later on. Otherwise, it was interesting to note the island of lowest inlet plenum pressure (and worst ISFC) occurred 
with IVC around $180^{\circ}$. When IVC occurs after $180^{\circ}$, the motion of the piston can push air back up in to the inlet system. When throttled, this resulted in slightly higher inlet plenum pressures and hence marginally lower pumping losses than incurred with IVC at $\sim 180^{\circ}$.
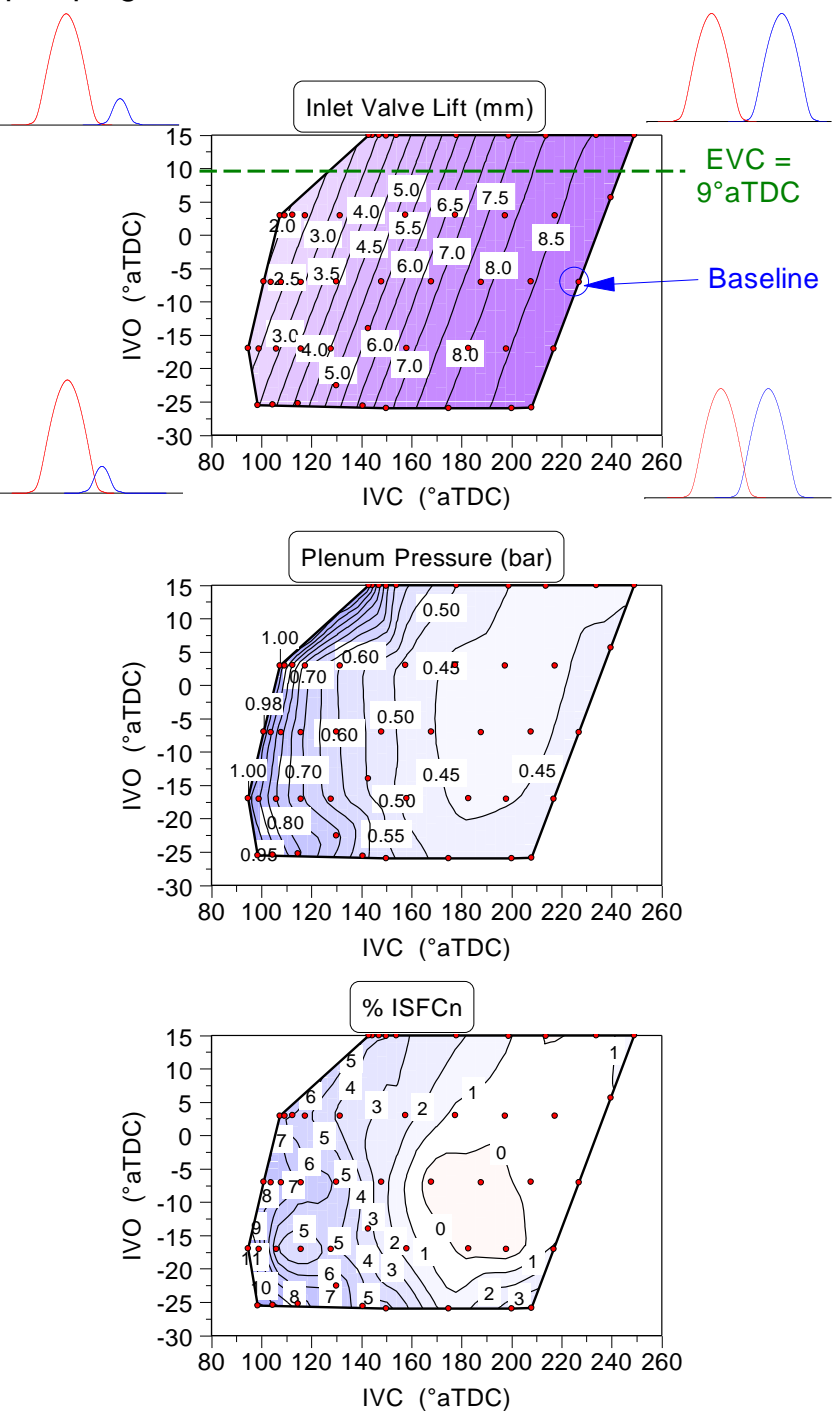

Figure 9: The effects of a fully variable inlet valvetrain at 1500rpm/3.2bar IMEPn (low valve overlap)

\section{EIVC \& Dual VVT Effects}

The next tests were concerned with combining a fully variable inlet valvetrain with exhaust VVT (a slightly higher cost solution but still feasible). As such, shown in Figure 10 are key measurements made at equivalent test conditions to those employed in Figure 9, but now with the exhaust event retarded by $34^{\circ}$ and EVC fixed at $43^{\circ}$ aTDC. An exhaust phase shift of $34^{\circ}$ is well within the capability of typical production cam phasers. Up to $\sim 13 \%$ improvement in fuel economy was possible c.f. a fixed valvetrain solution, with $\sim 6 \%$ benefit attributed to dual independent VVT and $\sim 7 \%$ associated with throttleless effects. At the site of minimum fuel consumption, the standard deviation in gross IMEP was still only 0.062 bar. However, advancing the inlet event beyond this point soon resulted in degradation in stability and hence fuel consumption. The $0-10 \%$ and $10-90 \%$ Mass Fraction Burned (MFB) periods were arguably more strongly influenced by increasing internal EGR than EIVC. However, this was not always the case as discussed later. The island of increased $0-10 \%$ MFB period at near-throttleless conditions was possibly associated with rapid reduction in plenum pressure and increased EGR pressure ratio as the throttle was initially closed.
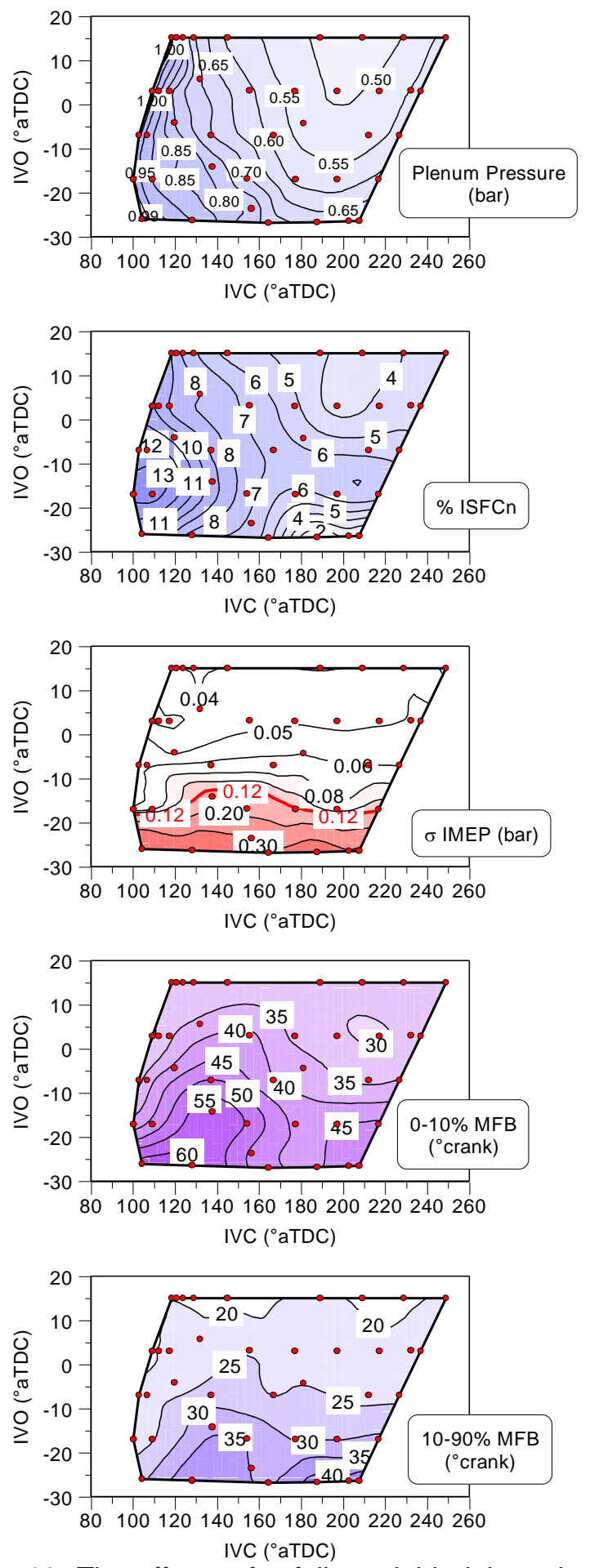

Figure 10: The effects of a fully variable inlet valvetrain at $1500 \mathrm{rpm} / 3.2 \mathrm{bar}$ IMEPn (high valve overlap) 

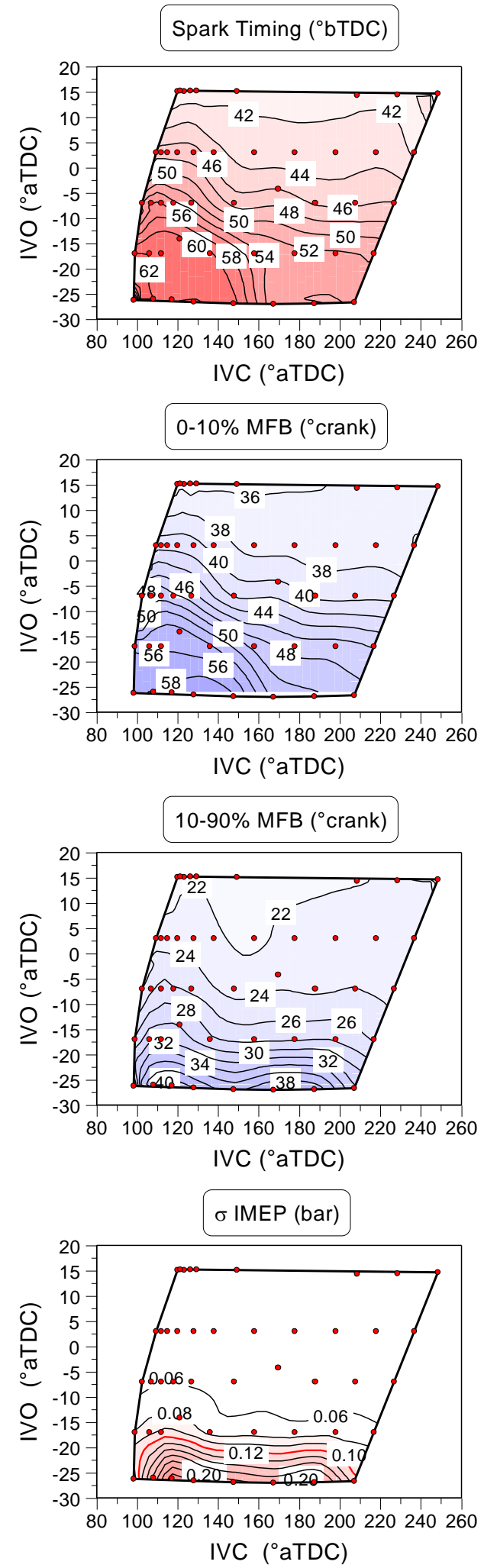

Figure 11: Combustion duration effects at 2000rpm/2.7bar IMEPn (high valve overlap)

\section{Combustion Duration Effects}

Shown in Figure 11 are maps of MBT spark timing, 0$10 \%$ MFB and $10-90 \%$ MFB periods when operating at $2000 \mathrm{rpm} / 2.7 \mathrm{bar}$ IMEPn. This data was generated under otherwise identical conditions to those used when producing Figure $10\left(\mathrm{EVC}=43^{\circ} \mathrm{aTDC}, \mathrm{EOI}=400^{\circ} \mathrm{bTDC}\right.$, $\lambda=1$ ). At such engine speed and load, the rate of mass burning slowed down with increased valve overlap as before. However, at this new site, the $0-10 \%$ MFB period was also more strongly affected by full throttleless EIVC operation. Such increase in $0-10 \%$ MFB period was also noted at low speeds under very light loads (and hence very low valve lifts) and this shall be returned to later on when discussing speed-load operating maps. Presumably these effects were associated with reduced in-cylinder turbulence under EIVC conditions, as reported elsewhere $(9,14,18)$. Optical measurements of the flow are ideally required at different speeds and valve lifts to confirm these observations.
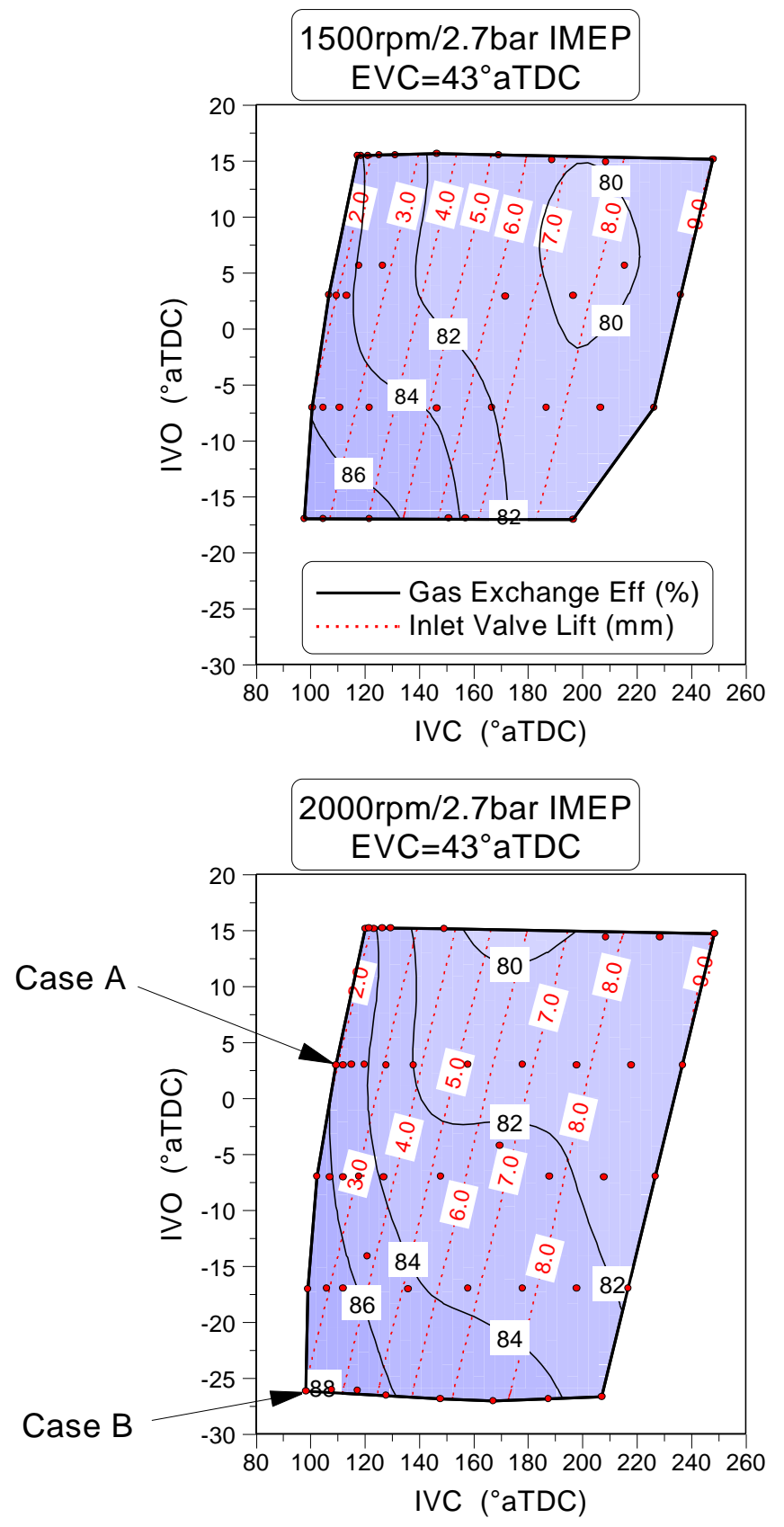

Figure 12: Gas exchange efficiency effects at 1500rpm and 2000rpm (2.7bar IMEPn, high valve overlap) 


\section{Gas Exchange Efficiency Effects}

Shown in Figure 12 are maps of gas exchange efficiency $\left(\eta_{G E}\right)$ at two speed-load sites (equivalent low load but varied engine speed). This efficiency was calculated as:

$$
\eta_{G E}=\frac{I M E P n}{I M E P g} \times 100
$$

These maps were produced under otherwise identical engine conditions (maximum exhaust valve lift, $E V C=43^{\circ}$ aTDC, MBT spark timings, $\quad \lambda=1$, $\mathrm{EOI}=400^{\circ} \mathrm{bTDC}$ ). Superimposed on the maps are lines of constant inlet valve lift. The engine was operating in full throttleless mode across the left-hand side of each map and the corresponding inlet plenum pressure maps are shown in Appendix B.

Two cases ("A" and "B") have been labelled on the 2000rpm map and can be used to help explain the fuel economy benefit of adding yet more internal EGR when an engine fitted with such a valvetrain is already operating in unthrottled EIVC mode. Firstly, the increased trapped residual mass occupies a greater proportion of the in-cylinder volume and therefore the inlet valve duration and lift must be increased to maintain load; rising from $107^{\circ} / 1.97 \mathrm{~mm}$ to $125^{\circ} / 2.99 \mathrm{~mm}$ from Case A to B. As a result, the pumping losses were significantly reduced, falling from $-0.449 \mathrm{bar}$ to $-0.377 \mathrm{bar}$ PMEP. This was probably associated with reduced throttling across the inlet valve itself and the corresponding reduction in pumping loop area can be seen in the log $p \log V$ diagram set out in Figure 13. The S-shaped curve in Figure 8 also helps illustrate how such throttling at the valve may be worse at the lowest inlet valve durations. The combustion remained stable at both of these sites and corresponding additional thermodynamic data has been included in Appendix $\mathrm{C}$.

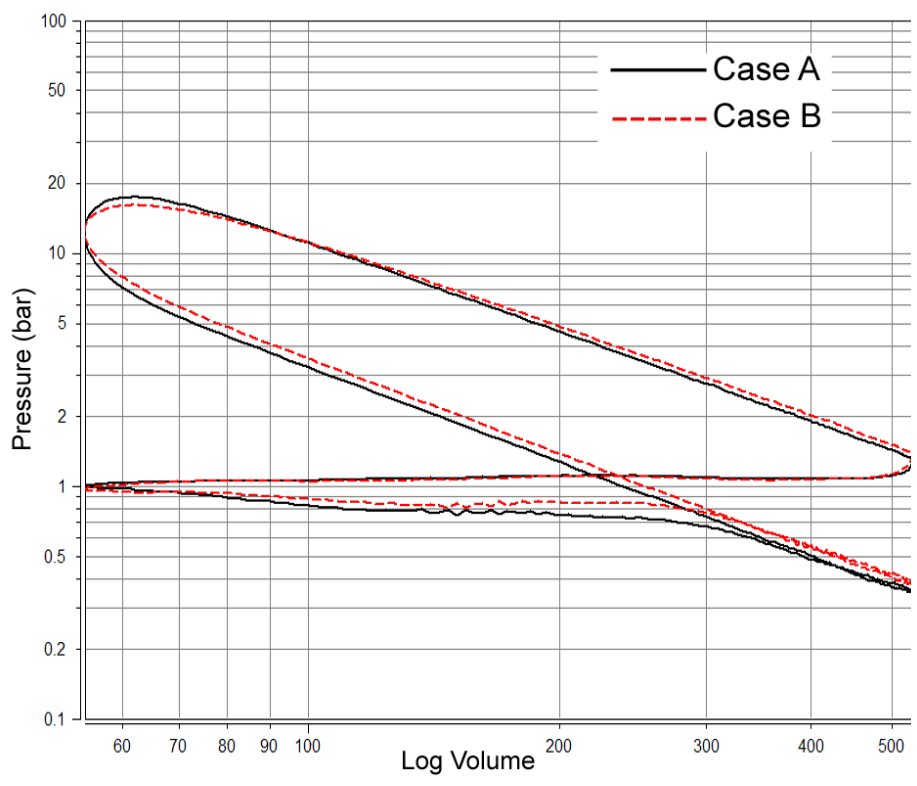

Figure 13: Log p Log V diagrams for Cases A and B
For Case $\mathrm{B}$, the higher pressure in the cylinder towards the end of the inlet and during compression was attributable to the reduced throttling at the valve but also the increased mass of residual within the cylinder. The improvement in pumping was significant, but another possible benefit of the additional internal EGR, in this case, was increased effective expansion ratio. When employing an EIVC strategy, the engine effectively acts as an "air-spring" until the piston has fallen and then risen back to a height equivalent to that at IVC. Thereafter, the in-cylinder gases are compressed above atmospheric (or near-atmospheric) pressure. In Case B, the inlet duration and lift were increased but the entire inlet event was actually further advanced, with IVC $12^{\circ}$ earlier in Case B at $98^{\circ}$ aTDC. During EIVC operation, if IVC can be advanced further by a certain phase, the effective compression stroke is decreased by an equivalent crank angle. In turn, this means the burning gases are effectively expanded further by an equivalent amount. To summarise, it appears that advancing both IVO and IVC when using a retarded high overlap strategy in combination with EIVC may sometimes enable further small improvements in thermal efficiency to be made.

In conclusion, most mechanical Variable Valve Actuation systems must endure low valve lift at low valve duration, which can lead to throttling at the valve itself. Under such circumstances, it seems the more EGR tolerated the better. Such benefits might of course be reduced if, for example, camless operation with trapezoidal wave valve lift profiles and/or faster rates of valve actuation could be practically achieved. Otherwise, in terms of maximising lift at low duration, the current VLD system performed relatively well for a mechanical system, with reasonably aggressive lift profiles achieved as seen in Figure 8.

\section{Speed-Load Operating Maps}

With the above observations understood, the effects of combining dual independent VVT with EIVC could be mapped across a speed-load window. The low-cost bottom-end available at the time of this work could only be used at up to 2000rpm. Nonetheless, a reasonable portion of the drive cycle could still be studied. Therefore, shown in Figure 14 is a comparison of VVT effects over such a window. The engine was operated at MBT spark timing, $\lambda=1$ and with $E O I=400^{\circ} \mathrm{bTDC}$ at all shown sites. The left-hand column of graphs was produced using VVT alone. The right-hand set was generated using VVT in combination with EIVC operation. This comparison was performed with identical values of valve overlap as shown in the top two figures, with EVC fixed at $43^{\circ}$ aTDC. The overlap used at each site was governed by that tolerated during the VVT+EIVC tests. However, beyond these overlap settings no additional improvements in fuel consumption could be made (with or without EIVC). Observing the maps, the overlap varied from $27^{\circ}$ to $70^{\circ}$, increasing with speed and load. This can be explained as at higher 
engine speeds there is usually less time for the EGR to be re-breathed from the exhaust manifold and hence higher overlap is required.

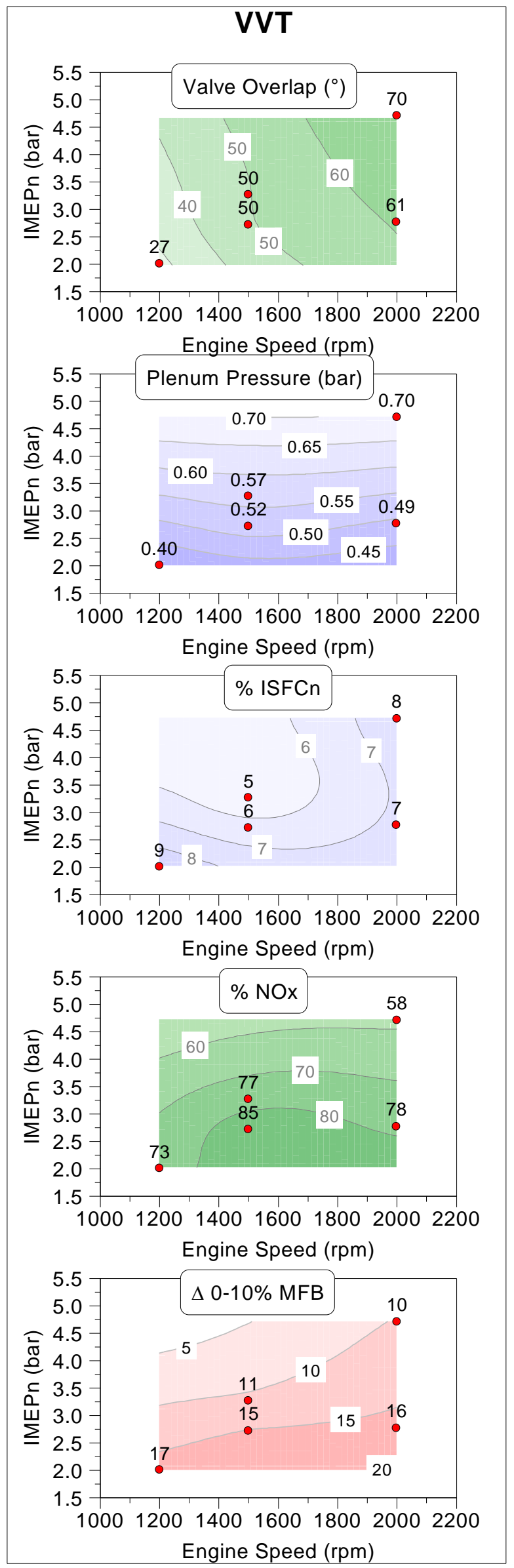

Figure 14: Speed-load maps (VVT versus VVT+EIVC)

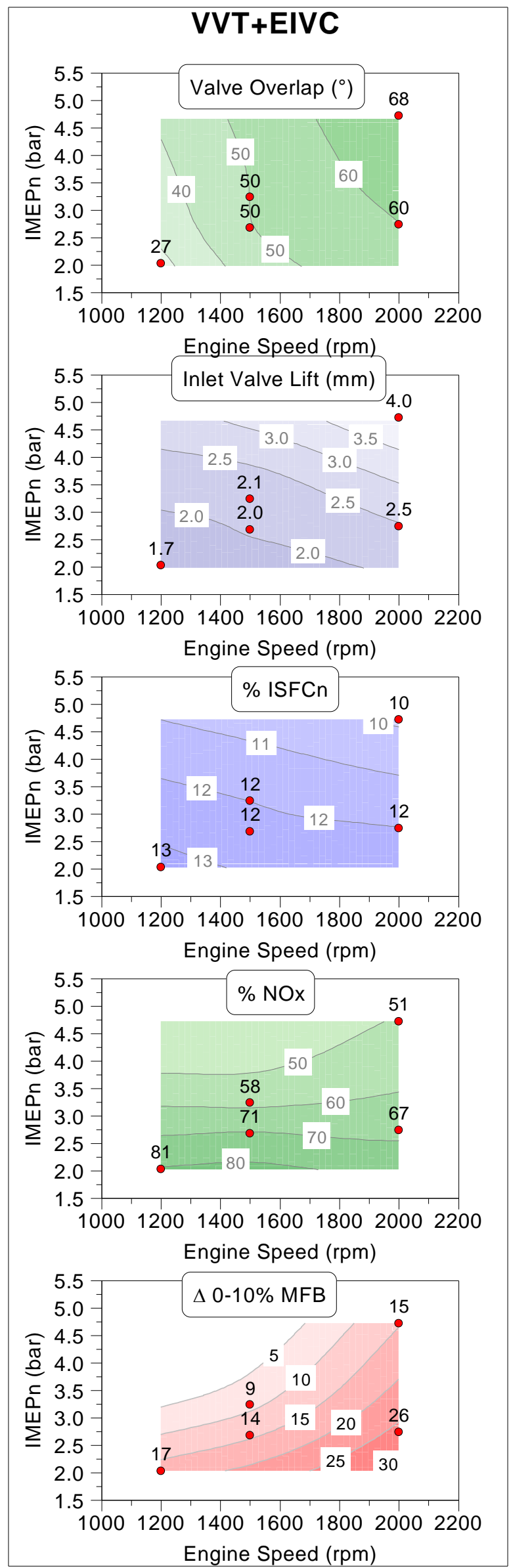


During the VVT-only tests, the engine was still operating under part-throttled conditions, with corresponding values of inlet plenum pressure shown. The increase in plenum pressure c.f. baseline non-VVT timing was between 0.06-0.18bar. When adopting VVT+EIVC, atmospheric inlet plenum pressures were achieved at all sites, as desired. Corresponding values of inlet valve lift have also been shown, varying from 1.7-4.0mm across the mapped regime and increasing with speed and load as expected.

At 2000rpm, it can be seen that the valve overlap increased with engine load. As output increases under unthrottled conditions, a longer inlet duration is required to inhale an increased mass of fresh charge. Assuming at least an equivalent percentage of EGR to that tolerated at lower load is still then required, a higher mass of residual would be needed and hence additional valve overlap would be necessary. The assumption of at least equivalent EGR rate is deemed sensible, given EGR tolerance is well known to increase with load in the SI engine (5). However a larger step change in overlap than observed here would be required to claim any significant improvement in such tolerance occurred here with such a small step change in load.

The values of percent ISFC shown in Figure 14 are expressed relative to the "baseline" valve timings described in Appendix A (throttled, non-VVT operation). The effects of VVT on fuel economy are also well understood and the improvements recorded are not too dissimilar to those reported in the literature (2-5). The additional use of EIVC allowed further improvements in ISFC of $6-8 \%$ at lower loads. At higher output, the benefit of EIVC operation dropped to $2 \%$. It is important to note that these benefits were recorded under stable conditions, with the highest value of $\sigma \mathrm{IMEP}$ across each map equal to 0.08 (VVT) and 0.075 (VVT+EIVC) respectively. When greater overlap to that shown was attempted this stability soon deteriorated (with or without EIVC).

The net IMEP values produced at the two 2000rpm sites were selected to match the indicated load produced at 2 bar and 4bar BMEP in a multi-cylinder production engine. Comparison of these two sites arguably gives some insight in to the indicated fuel economy gains available if such a valvetrain was to be adopted on an aggressively downsized engine. When capacity is reduced by $50 \%$, the brake output will approximately double for a given road-load requirement. By testing the engine at output equivalent to both $2 \mathrm{bar}$ and $4 \mathrm{bar}$ BMEP, it may be argued that some of the effects of halving an engines capacity can be uncovered. This simplistic approach of course neglects differences in compression ratio, in-cylinder flow, EGR tolerance, friction or in-vehicle gearing which will be necessary in many cases to best utilise the downsizing principle. Nonetheless, the data still highlights how the benefits of unthrottled EIVC operation are significantly reduced in proportion to any degree of downsizing employed. If capacity was to be halved, the benefit in indicated fuel economy would drop from $4.7 \%$ to $2.2 \%$ at the example 2000rpm cruising point.

Returning to the comparison of VVT versus VVT+EIVC, greater percent reduction in NOx was achieved at most sites when using VVT alone. This was probably associated with the fixed overlap condition, with higher amounts of internal EGR being trapped under partthrottled conditions, due to the partial-vacuum in the inlet and hence favourable EGR pressure ratio from exhaust to inlet during the overlap period.

Finally, values of the difference in $0-10 \%$ MFB period are also shown c.f. the "baseline" throttled non-VVT case. When employing VVT+EIVC, the corresponding isolines in the bottom right-hand figure indicate that the $0-10 \%$ MFB period was most heavily influenced by load at very low engine speeds. However, these isolines became more vertically inclined at the highest engine speed studied. Comparing the 1500rpm/2.7bar and 2000rpm/2.7bar sites, the 0-10\% MFB period increased by $12^{\circ}$ crank. The associated $0-10 \%$ MFB time period increased from $3.3 \mathrm{~ms}$ to $4.65 \mathrm{~ms}$ from $1500 \mathrm{rpm}$ to $2000 \mathrm{rpm}$, clearly demonstrating the combustion period was prolonged. Additional speed-load sites should be mapped in future work to confirm these observations but it seems efforts are required to increase the flame speed under light loads and also moderate engine speeds and this shall be returned to later on. Overall, the results of course neglect any friction losses of such a valvetrain. Unfortunately a single cylinder cannot provide a representative friction baseline due to the high degree of bottom-end friction and parasitic losses acting on the one cylinder alone.

\section{DIRECT FUEL INJECTION}

During the DI tests, the engine was fitted with a central direct fuel injector (prototype solenoid multi-hole) capable of operating at rail pressures of up to $120 \mathrm{bar}$. Otherwise, the engine remained unchanged. It is wellknown that adopting DI can allow an increase in geometric compression of 1-1.5 ratios for a given engine architecture and performance target. However, it was decided to leave the compression ratio unchanged $(9.8: 1)$ at this stage. This allowed evaluation of how well the central DI charge preparation performed vis-à-vis the PFI system, when combined with EIVC.

Shown in Figure 15(a) are the recorded values of ISFCn for the same PFI data set first introduced in Figure 9 and obtained at 1500rpm/3.2bar IMEPn conditions $\left(E V C=9^{\circ}\right.$ aTDC, MBT spark timing, $\lambda=1$ ). The "baseline" (throttled, non-VVT) case is labelled on this figure as is a reference "EIVC" case at equivalent overlap conditions. The first task with the DI system was to optimise both the fuel injection timing and pressure at both of these reference sites. Corresponding values of ISFCn produced during the $\mathrm{DI}$ "baseline" fuel injection 
optimisation tests are set out in Figure 15(b). This data was produced under conditions otherwise identical to the PFI tests. Shown in Figure 15(c) are corresponding values mapped at the equivalent DI "EIVC" site. Finally, set out in Table 2 are key parameters measured at the two "optimum" DI reference sites, also compared to the equivalent parameters measured under PFI conditions.

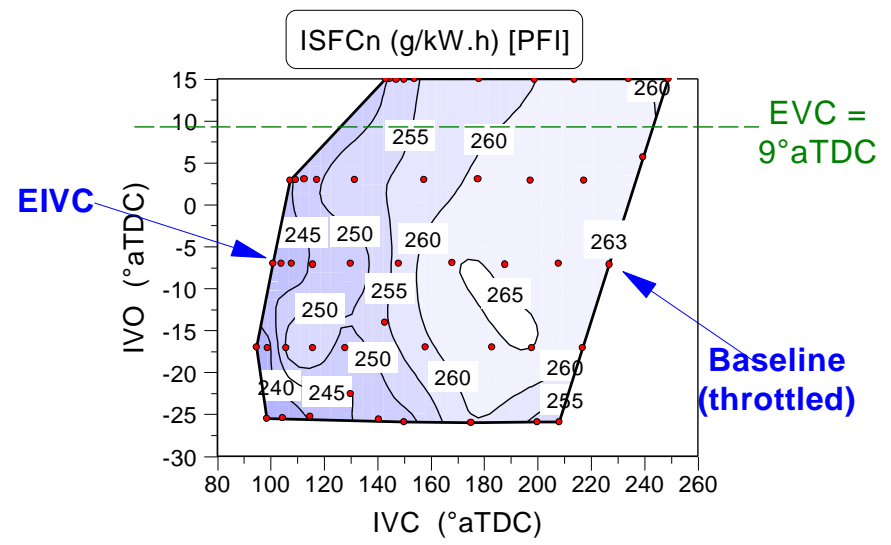

(a)

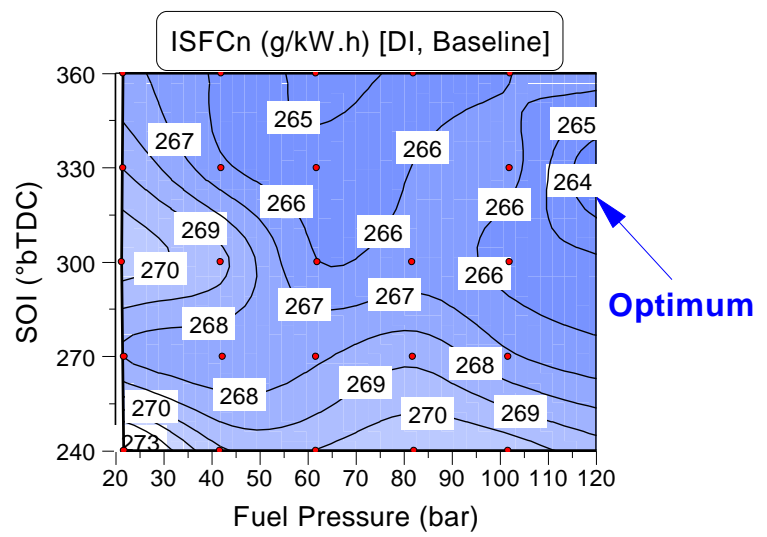

(b)

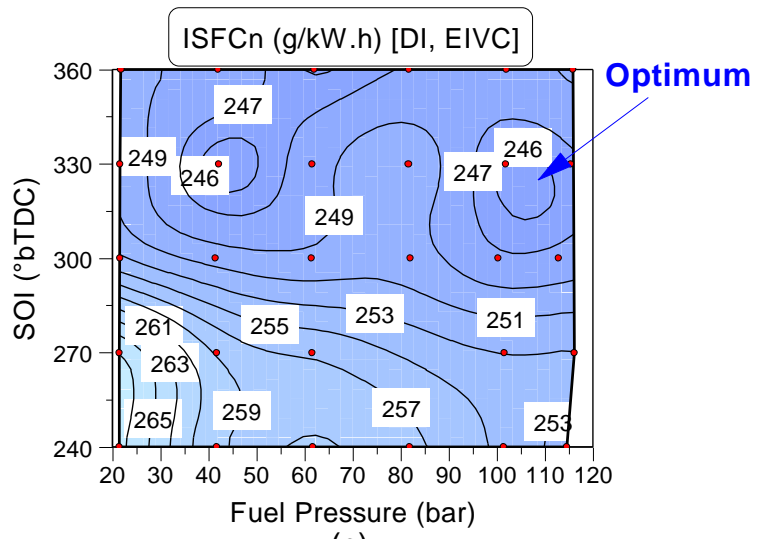

(c)

Figure 15: Values of ISFCn produced at 1500rpm/3.2bar IMEPn under (a) PFI and central DI conditions using (b) throttled and (c) unthrottled EIVC operation

Comparing the modes of injection under the throttled low valve overlap condition, the DI fuel consumption was only marginally higher than the PFI case. Associated with this marginal increase were higher engine-out emissions of unburned hydrocarbons. Nonetheless, under typical throttled SI engine conditions, the DI system appeared to be operating reasonably well (especially given the potential compression ratio increase had been omitted). However, under EIVC conditions, the DI setup did not perform quite as effectively, with reduced fuel consumption benefit c.f. PFI operation (6.8\% c.f. $7.2 \%$ ), prolonged $0-10 \%$ MFB period, worse combustion stability and substantial increase in engine-out THC emissions.

\begin{tabular}{|c|c|c|c|c|}
\hline & \multicolumn{2}{|c|}{ PFI } & \multicolumn{2}{|c|}{ DI } \\
\hline & Baseline & EIVC & Baseline & EIVC \\
\hline SOI ('bTDC) & - & - & 330 & 330 \\
\hline $\begin{array}{l}\text { Fuel Press } \\
\text { (bar) }\end{array}$ & 3.5 & 3.5 & 120 & 100 \\
\hline Inlet dur. $\left({ }^{\circ}\right)$ & 234 & 108 & 234 & 105 \\
\hline Inlet lift (mm) & 8.98 & 2.04 & 8.98 & 1.9 \\
\hline $\begin{array}{l}\text { Inlet Press } \\
\text { (bar) }\end{array}$ & 0.46 & 1.0 & 0.45 & 1.0 \\
\hline ISFC (g/kW.h) & 263 & 244 & 264 & 246 \\
\hline THC (ppm) & 2445 & 2567 & 3167 & 3725 \\
\hline $\mathrm{CO}(\%)$ & 1.02 & 0.7 & 0.99 & 0.75 \\
\hline NOx (ppm) & 2944 & 2723 & 2702 & 2579 \\
\hline бIMEPg (bar) & 0.053 & 0.069 & 0.044 & 0.075 \\
\hline$\eta_{\mathrm{GE}}(\%)$ & 83.1 & 88.1 & 82.4 & 87.9 \\
\hline $\operatorname{APmax}\left({ }^{\circ}\right)$ & 14.1 & 14.8 & 14.8 & 14.1 \\
\hline Pmax (bar) & 21.7 & 19.4 & 20.6 & 19.2 \\
\hline $\operatorname{Rmax}\left(\mathrm{bar} /{ }^{\circ}\right)$ & 0.74 & 0.67 & 0.68 & 0.6 \\
\hline MBT Spark $\left(^{\circ}\right)$ & 28.4 & 29.4 & 26.6 & 35.9 \\
\hline $0-10 \% \operatorname{MFB}\left({ }^{\circ}\right)$ & 24.2 & 26.2 & 23.6 & 29.9 \\
\hline $10-90 \% \operatorname{MFB}\left({ }^{\circ}\right)$ & 16.9 & 16.6 & 16.9 & 20.8 \\
\hline
\end{tabular}

Table 2: Key parameters measured with each mode of injection (low valve overlap)

\begin{tabular}{|c|c|c|c|c|}
\hline & \multicolumn{2}{|c|}{ PFI } & \multicolumn{2}{|c|}{ DI } \\
\hline & Baseline & EIVC & Baseline & EIVC \\
\hline SOI ('bTDC) & - & - & 360 & 300 \\
\hline $\begin{array}{l}\text { Fuel Press } \\
\text { (bar) }\end{array}$ & 3.5 & 3.5 & 120 & 115 \\
\hline Inlet dur. $\left(^{\circ}\right)$ & 234 & 110 & 234 & 109 \\
\hline Inlet lift (mm) & 8.98 & 2.13 & 8.98 & 2.08 \\
\hline $\begin{array}{l}\text { Inlet Press } \\
\text { (bar) }\end{array}$ & 0.57 & 1.0 & 0.57 & 1.0 \\
\hline ISFC (g/kW.h) & 249 & 231 & 251 & 240 \\
\hline THC (ppm) & 2367 & 2556 & 2950 & 3657 \\
\hline $\mathrm{CO}(\%)$ & 0.96 & 0.48 & 0.82 & 0.73 \\
\hline NOx (ppm) & 687 & 1239 & 832 & 1453 \\
\hline бIMEPg (bar) & 0.058 & 0.06 & 0.062 & 0.062 \\
\hline$\eta_{\mathrm{GE}}(\%)$ & 85.8 & 89.9 & 84.8 & 88 \\
\hline $\operatorname{APmax}\left({ }^{\circ}\right)$ & 13.7 & 14 & 14.22 & 14.23 \\
\hline Pmax (bar) & 21.5 & 19.5 & 20.8 & 18.6 \\
\hline $\operatorname{Rmax}\left(\right.$ bar $\left./{ }^{\circ}\right)$ & 0.6 & 0.6 & 0.56 & 0.53 \\
\hline MBT Spark $\left(^{\circ}\right)$ & 40.6 & 37.8 & 36.9 & 42.5 \\
\hline $0-10 \% \operatorname{MFB}\left({ }^{\circ}\right)$ & 35.1 & 33.1 & 32.5 & 36.6 \\
\hline $10-90 \%$ MFB $\left({ }^{\circ}\right)$ & 23.7 & 20.7 & 24.2 & 2.07 \\
\hline
\end{tabular}

Table 3: Key parameters measured with each mode of injection (high valve overlap) 
Set out in Table 3 are equivalent measurements obtained under high overlap conditions, with IVO $=7^{\circ} \mathrm{bTDC}$ and $\mathrm{EVC}=43^{\circ} \mathrm{aTDC}$. Again, the DI data was that considered to be the optimum as derived from maps equivalent to those in Figure 15. In summary, under increased overlap conditions, the DI system again performed well during throttled operation but poorly with EIVC. The relative benefit in fuel economy from EIVC reduced from $7.2 \%$ in $\mathrm{PFI}$ mode to $4.4 \%$ when combined with DI. Optical measurements are required to fully understand the problems with the DI setup in high overlap EIVC mode. However, it was concluded that such a DI system, performing well during conventional throttled SI engine operation, may well need significant re-design if to be used with EIVC operation. The effects of modified combustion chamber design and increased compression ratio will be studied in future work.

\section{INLET PORT MASKING}

The above results indicate that increased EGR tolerance may allow yet further fuel savings to be made. Recent work has therefore been concerned with re-designing the inlet ports in an attempt to increase the in-cylinder turbulence levels with minimal trade-off in valve discharge coefficient. The method investigated is that commonly referred to as inlet port masking and involves shrouding the back of the inlet valves in an attempt to increase forward tumble and hence in-cylinder gas velocities at the time of ignition, as reported elsewhere $(14,18)$.

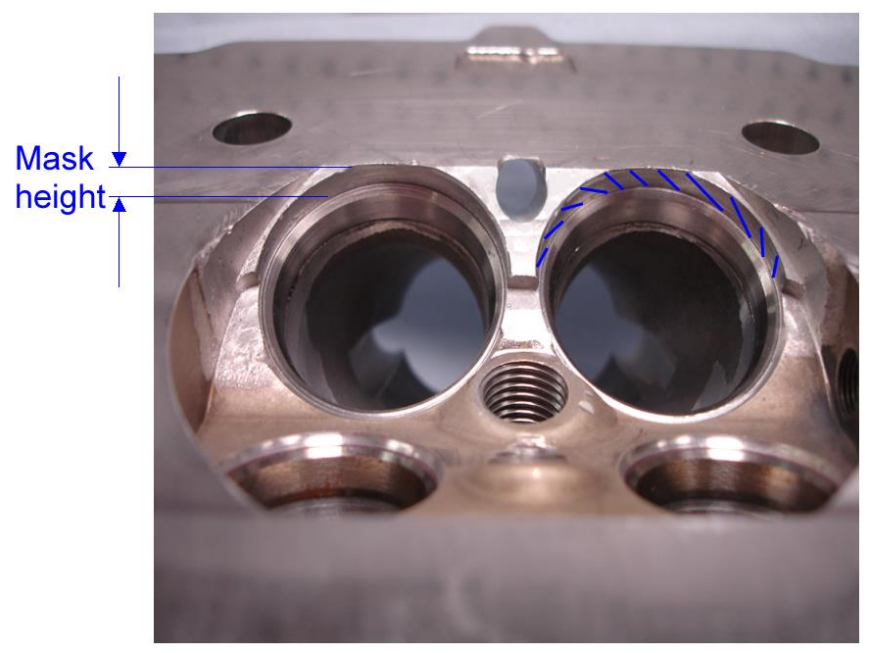

Figure 16: Inlet port masking optimised on a steady state cylinder head flow rig (right-hand masked area shown hatched)

Set out in Figure 16 is a picture of the modified combustion chamber, with the new inlet port masks indicated. These masks shrouded the back of each valve through $180^{\circ}$ and were positioned symmetrically and equivalently on each valve. Masks of reduced arc $\left(\sim 100^{\circ}\right)$ were also initially examined but these proved to be relatively ineffective. In order to optimise the mask height, the cylinder head was fitted to an in-house steady state cylinder head flow rig. This rig was designed to draw air through the inlet ports, with a constant pressure drop maintained across the head. The head itself mounted at right angles to a liner assembly that included an impulse torque meter to measure the tumble ratio achieved. This right-angled installation allowed tumble to be measured on a rig otherwise setup for axial swirl measurements. In brief, such a rig is common throughout industry and provides a useful means for qualitative comparison of tumble under steady state conditions, albeit with piston motion and the associated in-cylinder effects neglected. A valve jacking plate was used to open the valves to each desired lift and evaluate the influence of different mask heights at varied valve openings.

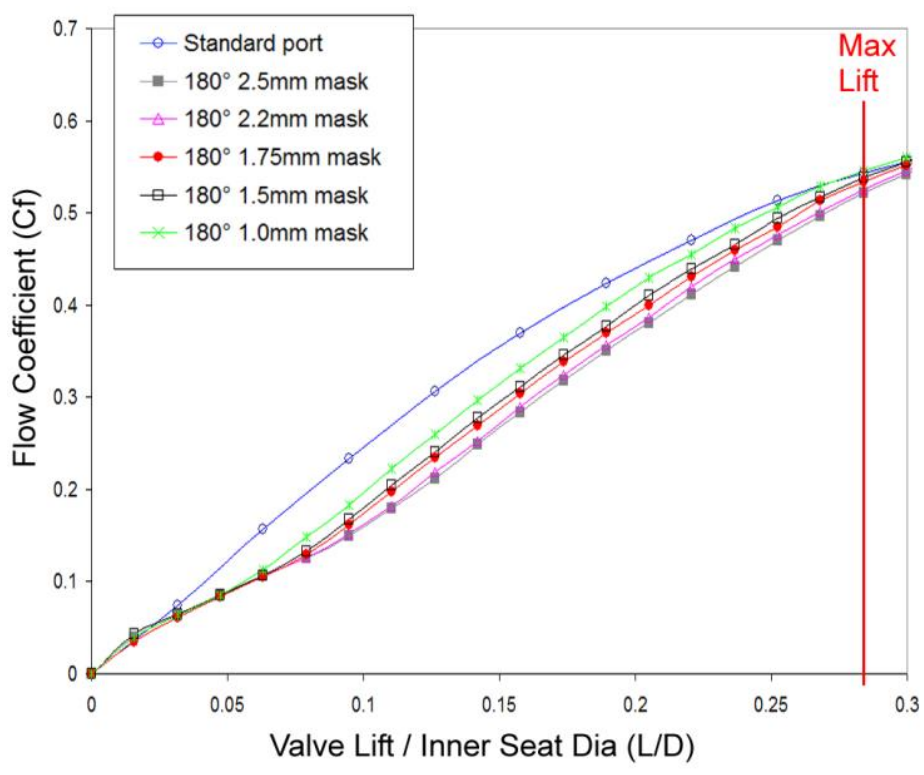

Figure 17: Inlet port flow coefficients observed with different inlet port mask heights

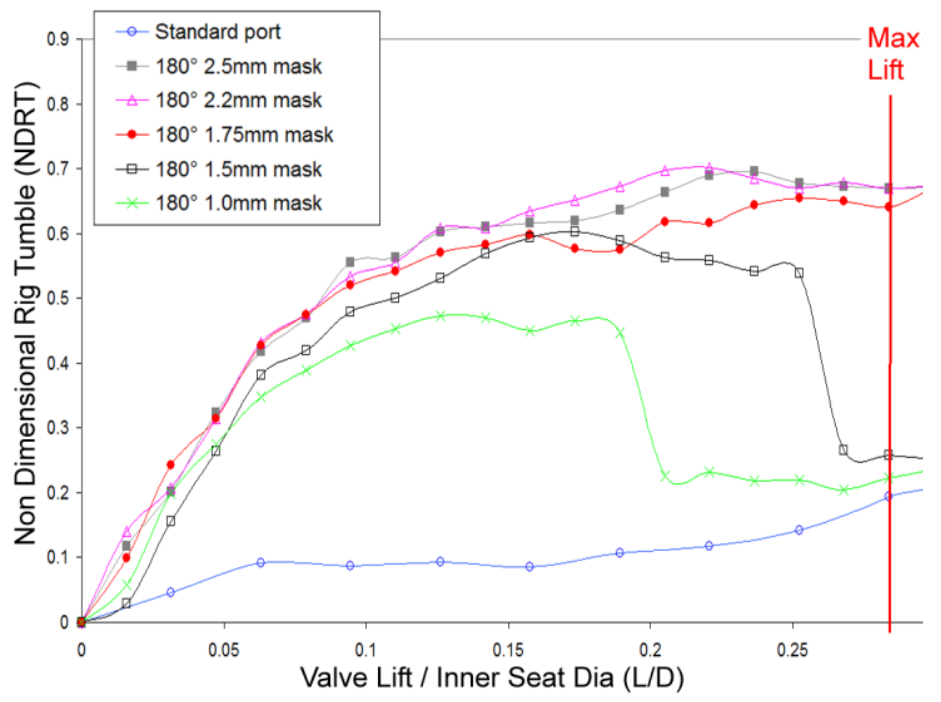

Figure 18: NDRT observed with different inlet port mask heights 
Set out in Figure 17 are the inlet port flow coefficients observed with the different mask heights considered. This coefficient describes the ratio of measured to theoretical mass flow (with the latter assumed to be through an ideal convergent nozzle). Shown in Figure 18 are corresponding values of Non Dimensional Rig Tumble (NDRT). This parameter describes the ratio of angular to axial momentum and may be considered as a qualitative indicator of tumble. Observing the data, the $2.2 \mathrm{~mm}$ mask provided the best compromise, with NDRT values vastly improved throughout port opening. The original port can be considered to be relatively neutral, with no tumble flap fitted to the inlet in the current work. As would be expected, the increase in tumble was at the expense of flow coefficient but the effect with the $2.2 \mathrm{~mm}$ mask at maximum lift appeared acceptable. However, the influence on full load volumetric efficiency still needs to be quantified. The sudden decline in mid-range NDRT as the height of the mask was reduced was associated with the valve passing beyond the mask and allowing an alternative flow path into the chamber, flow detachment and rapid deterioration in tumble. In summary, the results demonstrate that increased forward tumble has potentially been achieved and mapping work is currently underway to evaluate the effect of such masks under firing engine conditions.

\section{CONCLUSION}

The effects of combining EIVC with internal EGR were studied in a thermodynamic single cylinder research engine under both port and direct fuel injection conditions.

During unthrottled (EIVC) port-fuelled engine operation, the following conclusions were made:

- At the typical part-load mapping site of 1500rpm/3.2bar IMEP, EIVC operation allowed fuel consumption reductions of up to $8 \%$. The addition of inlet VVT allowed further savings of up to $3 \%$. Exhaust VVT then enabled yet more small improvements of $2 \%$.

- The maximum fuel economy benefits achieved were limited by increased $0-10 \%$ mass fraction burned periods and the onset of unstable combustion. This effect seemed most limiting at low speed and very low loads (very early IVC with the lowest valve lifts) but also moderate loads at higher speeds.

- During unthrottled EIVC conditions at constant speed and load, increasing the valve overlap and hence internal EGR rate allowed greater inlet valve duration and lift to be used. In turn, this reduced the throttling across the inlet valves and resulted in higher gas exchange efficiency and small additional fuel savings.
- Advancing both IVO and IVC when using a retarded high overlap strategy in combination with EIVC allowed increased effective expansion and hence further small improvements in thermal efficiency.

- Most mechanical EIVC systems must endure relatively low valve lifts at low valve durations, which can lead to throttling at the valve itself. It would therefore appear that the more EGR tolerated, the better.

- Under 50\%-downsized conditions, the fuel economy benefit of EIVC operation fell from $4.7 \%$ to $2.2 \%$ at a typical $2000 \mathrm{rpm}$ cruising site.

When switching to homogeneous central direct fuel injection operation, the additional observations were made:

- At the same typical part-load 1500rpm site, under conventional throttled conditions the central DI charge preparation performed reasonably well, both with and without high valve overlap.

- When using EIVC and VVT, the DI system performed poorly, with fuel economy benefit dropping to $4.4 \%$ c.f. $7.2 \%$ in PFI mode, despite re-optimisation of the injection timing and pressure. Optical measurements are required to fully understand these effects.

Future work shall be concerned with the effects of the inlet port masks, so far only optimised on the flow bench, on combustion, performance and emissions when operating in such throttleless modes.

\section{ACKNOWLEDGMENTS}

Thanks to Mark Potts, Hugh Blaxill and Neil Fraser of MAHLE Powertrain and Oliver Fritz and Joerg Reuckauf of MAHLE ZRV for their support.

\section{REFERENCES}

1. Louis, J.J.J.: "Well-To-Wheel Energy Use and Greenhouse Gas Emissions for Various Vehicle Technologies", SAE Paper No. 2001-01-1343, (2001).

2. Kramer, U. and Phlips, P.: "Phasing Strategy for An Engine With Twin Variable Cam Timing", SAE Paper No. 2002-01-1101, (2002).

3. Moro, D., Minelli, G. and Serra, G.: "Thermodynamic Analysis of Variable Valve Timing Influence on SI Engine Efficiency", SAE Paper No. 2001-01-0667, (2001). 
4. Roberts, C.E. and Stanglmaier, R.H.: "Investigation of Intake Timing Effects on the Cold Start Behaviour of a Spark Ignition Engine", SAE Paper No. 199901-3622, (1999).

5. Cairns, A., Irlam, G. and Blaxill, H.: "Exhaust Gas Recirculation for Improved Part and Full Load Fuel Economy in a Turbocharged Gasoline Engine", SAE Paper No. 2006-01-0047, (2006).

6. Schäfer, J. and Balko, J.: "High Performance Electric Camshaft Phasing System", SAE Paper No. 200701-1294, (2007).

7. Tuttle, J.: "Controlling engine load by means of Late Intake Valve Closing", SAE Paper No. 800794, (1980).

8. Tuttle, J.: "Controlling engine load by means of Early Intake Valve Closing", SAE Paper No. 820408, (1982).

9. Cleary D., Silvas G.: "Unthrottled Engine Operation with Variable Intake Valve Lift, Duration and Timing", SAE Paper No. 2007-01-1282, (2007).

10. Hannibal, W., Flierl, R., Stiegler, L. and Meyer, R.: "Overview of Current Continuously Variable Valve Lift Systems for Four-Stroke Spark-Ignition Engines and the Criteria for their Design Ratings", SAE Paper No. 2004-01-1263, (2004).

11. Sauer, C., Kulzer, A., Rauscher, M. and Hettinger, A.: "Analysis of Different Gasoline Combustion Concepts with Focus on Gas Exchange", SAE Paper No. 2008-01-0427, (2008).

12. Allen, J. and Law, D.: "Advanced Combustion Using a Lotus Active Valve Train: Internal Exhaust Gas Recirculation Promoted Auto-Ignition", Proceedings of the IFP International Congress 2001, p.p. 85-100, (2001).

13. Koopmans, L., Strom, H., Lundgren, S., Backlund, O. and Denbratt, I.: "Demonstrating a SI-HCCl-SI Mode Change on a Volvo 5-Cylinder Electronic Valve Control Engine", SAE Paper No. 2003-010753, (2003).

14. Unger, H., Schneider, J., Schwarz, C. and Kock, KF., "VALVETRONIC - Experience from 7 years of Series Production and a Look into the Future", 29. International Wiener Motorensymposium, (2008).

15. Shimizu, K., Fuwa, N., Yoshihara, Y. and Hori, K.: “ The New Toyota variable Valve Timing and Lift System", Aachener Kolloquium Fahrzeug und Motorentechnik, (2007).

16. Tsuruta, S.: "The Innovative Variable Valve Event and Lift System (VVEL) for the New Nissan V6 and V8 Engine", 29. International Wiener Motorensymposium, (2008).

17. Fujita, T., Onogawa, K., Kiga, S., Mae, Y., Akasaka, Y. and Tomogane, K.: "Development of Innovative Variable Valve Event and Lift (VVEL) System", SAE Paper No. 2008-01-1349, (2008).

18. Sellnau, M., Kunz, T., Sinnamon, J. and Burkhard, J.: "2-step Variable Valve Actuation: System Optimisation and Integration on an SI Engine", SAE Paper No. 2006-01-0040, (2006).
19. Stansfield P.A., Wigley G., Garner C.P., Patel R., Ladommatos N., Pitcher G., Turner J.W.G., Nuglisch $\mathrm{H}$., Helie J.: "Unthrottled Engine Operation using Variable Valve Actuation: The Impact on the Flow Field, Mixing and Combustion", SAE Paper No. 2007-01-1414, (2007).

20. Patel, R., Ladommatos, N., Stansfield, P., Wigley, G., Garner, P., Pitcher, G., Turner, J.W.G. and Nuglisch, $H .:$ "Comparison between Unthrottled, Single and Two-valve Induction Strategies Utilising Direct Gasoline Injection: Emissions, Heat-release and Fuel Consumption Analysis", SAE Paper No. 2008-01-1626, (2008).

21. Malcolm, J.S., Aleiferis, P.G., Todd, A.R., Cairns, A., Hume, A., Blaxill, H., Hoffmann, H. and Rueckauf, J.: "A Study of Alcohol Blended Fuels in a New Optical Spark Ignition Engine", IMechE Performance, Fuel Economy and Emissions Conference, London, (2007).

22. Malcolm, J.S., Aleiferis, P.G., Todd, A.R., Cairns, A., Hoffmann, $H_{\text {.: }}$ "An Optical Study of Spray Development and Combustion of Ethanol, IsoOctane and gasoline Blends in a DISI Engine", SAE Paper No. 2008-01-0073, (2008).

23. Lancefield, T., Lawrence, T., Ahmed, A. and Hamouda, H.B.H.: "VLD - A flexible, modular, cam operated VVA system giving variable valve lift and duration and controlled secondary valve openings", SIA Conference on Variable Valve Actuation, IFP Rueil, (2006).

24. Bunsen, E., Grote, A., Willand, J., Hoffmann, H., Fritz, O. and Senjic, S.: "Fuel consumption improvements by variation of intake valve lift and timing - A mechanically fully variable valvetrain system for a 1.6l gasoline engine with direct injection", Haus der Technik Variable Valvetrain Congress, (2007).

\section{CONTACT}

Dr. Alasdair Cairns, MAHLE Powertrain Ltd., Costin House, St. James Mill Rd., Northampton, NN5 5TZ, U.K. Tel: +44(0)870 157 3380, Fax: +44(0)870 157 3100, Email: alasdair.cairns@gb.mahle.com

\section{DEFINITIONS, ACRONYMS, ABBREVIATIONS}
AFR: Air-to-Fuel Ratio
APmax: Angle of Peak Pressure
BMEP: Brake Mean Effective Pressure
BSFC: Brake Specific Fuel Consumption
c.a.: Crank Angle
DI: Direct Injection
EGR: Exhaust Gas Recirculation
EIVC: Early Inlet Valve Closing
EOI: End of Injection
EVC: Exhaust Valve Closing 
EVO: Exhaust Valve Opening

FSI: Fuel Stratified Injection

IVC: Inlet Valve Closing

IVO: Inlet Valve Opening

IMEPg: Gross Indicated Mean Effective Pressure

IMEPn: Net Indicated Mean Effective Pressure

ISFCn: Net Indicated Specific Fuel Consumption

MBT: Maximum Brake Torque

MFB: Mass Fraction Burned

MOP: Maximum Opening Position

MPT: MAHLE Powertrain

NA: Naturally Aspirated

NDRT: Non Dimensional Rig Tumble

NEDC: New European Drive Cycle

OEM: Original Equipment Manufacturer

PFI: Port Fuel Injection

Pmax: Maximum in-cylinder pressure

Rmax: Maximum rate of pressure rise

RON: Research Octane Number

SOI: Start of Injection

SI: Spark Ignition

TDC: Top Dead Centre

THC: Total Unburned Hydrocarbons

ULG: Unleaded Gasoline

VVT: Variable Valve Timing

WOT: Wide Open Throttle

$\eta_{\text {GE }}$ : Gas exchange efficiency

$\lambda$ : Relative air-to-fuel ratio

$\sigma:$ Standard deviation

\section{APPENDIX A - VVT DATABASE}

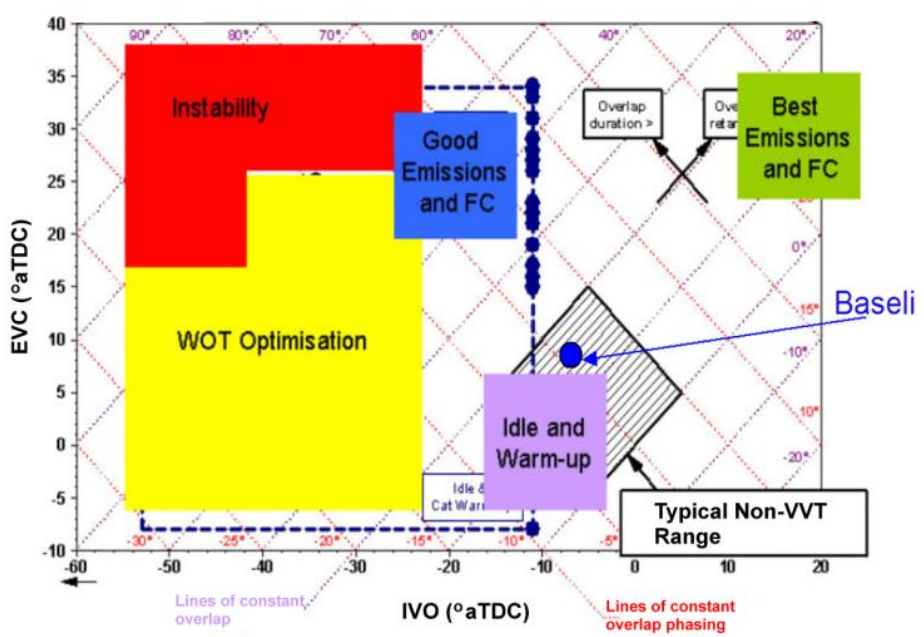

Figure A1: Valve overlap diagram showing different VVT operating strategies

Shown in Figure A1 is a map of typical valve overlap operating regimes, produced from an experimental database for numerous engines tested at MPT. The cross-hatched diamond shaped regime superimposed in the middle of the figure illustrates the typical area in which the non-VVT production SI engines tested must operate to best compromise between acceptable combustion stability at idle, part-load fuel efficiency and high load performance. The "baseline" condition used in the current work is also shown marked on the figure and can be seen to lie within this typical non-VVT valve timing regime. However, the fact that a single cylinder was used must be kept in mind, with potential cylinderto-cylinder interactions omitted.

\section{APPENDIX B - INLET PRESSURE DATA}

Shown in Figure B1 are maps of inlet plenum pressure for the data sets first introduced in Figure 12. These maps have been appended to demonstrate that full throttleless operation was achieved at all sites at the lefthand side of the maps.
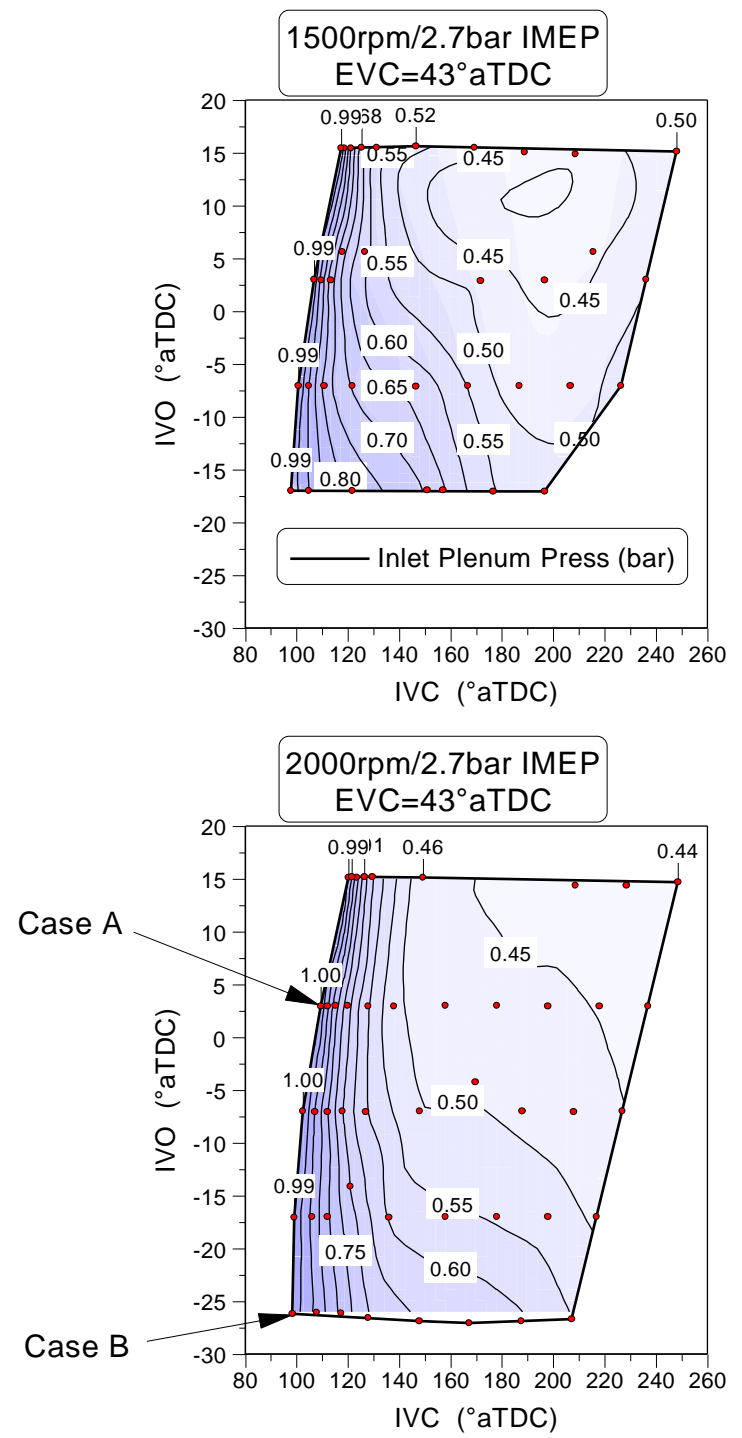

Figure B1: Inlet plenum pressure at $1500 \mathrm{rpm}$ and 2000rpm (2.7bar IMEPn) 


\section{APPENDIX C - THERMODYNAMIC DATA}

Shown in Table C1 are key thermodynamic parameters at the two test sites referred to as Case A and Case B. This data has been included to demonstrate that acceptable combustion was achieved at both sites, albeit with prolonged combustion duration in Case B.

\begin{tabular}{|c|c|c|}
\hline & Case A & Case B \\
\hline Inlet Press (bar) & 1.0 & 0.99 \\
\hline ISFC (g/kW.h) & 235 & 233 \\
\hline THC (ppm) & 1829 & 1973 \\
\hline $\mathrm{CO}(\%)$ & 0.39 & 0.54 \\
\hline NOx (ppm) & 1467 & 544 \\
\hline бIMEPg (bar) & 0.055 & 0.088 \\
\hline$\eta_{\mathrm{GE}}(\%)$ & 85.9 & 88.0 \\
\hline $\operatorname{APmax}\left({ }^{\circ}\right)$ & 14.3 & 14.4 \\
\hline Pmax (bar) & 16.6 & 15.5 \\
\hline $\operatorname{Rmax}\left(\right.$ bar $\left./{ }^{\circ}\right)$ & 0.49 & 0.37 \\
\hline MBT Spark $\left(^{\circ}\right)$ & 47.2 & 64 \\
\hline $0-10 \% \operatorname{MFB}\left({ }^{\circ}\right)$ & 41 & 58 \\
\hline $10-90 \%$ MFB $\left(^{\circ}\right)$ & 23 & 33 \\
\hline
\end{tabular}

Table C1: Comparison of key combustion parameters 